that is, a predrift position to the north. But Kent and Tarling were not so sure, citing a major geological argument against a northern position. In the vicinity of Kenya-Tanzania there are thick sediments apparently deposited from the Upper Carboniferous onwards, both onshore and out to several hundred kilometres offshore. So how, Kent and Tarling asked, could these deposits "exist in their present position if this was occupied by a microcontinent that has since moved away"?

They then went on to question both the validity of the palaeomagnetic data and the significance of the analysis based on them. The point about validity hinged on whether or not the measured sediments had been remagnetised since they were laid down. But Kent and Tarling argued that even if remagnetisation could be ruled out and the data were perfectly valid, there is at least one alternative way of comparing the Madagascar data with those from other landmasses. And this other way suggests that a southward drift of Madagascar is no more likely than a northward drift or no drift at all. The point was not that one method is any better or worse than the other, but simply that both are equally valid and reasonable.

Be that as it may, there is now a sequel. Since Embleton and McElhinny reported their first data, palaeomagnetic investigations of Madagascan rocks have continued (both in Australia and France) to the point where there is now an almost complete palaeomagnetic coverage of the Karroo Supergroup from the Upper Carboniferous to the Middle Jurassic. And all of the results have been brought together and analysed by McElhinny et al.

The Madagascan data fall into three sets covering, respectively, the timespans: (1) Upper Carboniferous to Lower Permian, (2) Upper Permian to Lower Triassic and (3) Middle Triassic to Middle Jurassic. Unfortunately, appropriate African data are heavily biassed towards the Middle TriassicMiddle Jurassic, which makes comparison over the total Karroo period difficult.

And the results of the comparison are striking. Taking the time-spans (1), (2) and (3) together, the average angular difference between the Madagascan and African-South American pole positions is $16.8^{\circ}$ for Madagascar in the southern predrift position and $15.3^{\circ}$ assuming the island to have maintained its present position. These are palacomagnetically significant differences. By contrast, the average angular difference for Madagascar in the northern predrift position is only $4.5^{\circ}$, which is palaeomagnetically insignificant. Moreover, these averages conceal no anomalies; time-spans (1), (2) and (3) taken separately each give a similar result.

In short, the palaeomagnetic case for the northern predrift position of Madagascar is, in the word of McElhinny and his colleagues, "unequivocal". Even the sceptics must surely agree that at the very least the case is strong. It is difficult to believe that the palaeomagnetic data are not valid. Remagnetisation, for example, is possible, but hardly likely in view of the similar results for the three time-spans and the number of different rock types involved. So it would appear that someone has a lot of reconciling to do.

\section{Competition and sexual dimorphism in plants}

\section{from Peter D. Moore}

As members of a species in which males and females are increasingly coming into competition with one another, it is interesting for us to consider the evolutionary consequences which have resulted from such a state of affairs in other species. Sexual dimorphism is the term used for situations in which the male and female of a species are adapted so that they draw on different resources, or tap a resource in different ways. It results from conditions where the limitations of the environment can produce deleterious competitive interactions between males and females inhabiting the same area.

Sexual dimorphism is quite common among animals and may result in considerable differences between the sexes. In many birds of prey, such as the sparrow hawk (Accipiter nisus) the male is considerably smaller than the female. The two sexes feed on different prey species, the male concentrating on smaller, more agile species, and the female on larger ones.

Among plants, very few examples of sexual dimorphism have been described. Obviously it could exist only within dioecious species, where the sexes are separate. One example is the sheep's sorrel (Rumex acetosella) which was studied by Putwain and Harper (J. Ecol., 60, 113; 1972). Here the two sexes were found growing together, but showed considerable differences in their times of growth and in the allocation of food reserves. Male plants grew faster in the spring, but expended less energy on the production of inflorescences and pollen than did the female on sced production. Female plants were later in their growth, but finally developed a taller canopy. Males invested more energy in the production of roots and vegetative offshoots. Males and females thus tap the environmental resources at different times and in rather different ways, constituting an example of niche diversification between the sexes,

Freeman, Klikoff and Harper (Science, 193, 597; 1976) have examined several dioecious plant species in relation to soil moisture in arid to semiarid habitats in Utah. They found that the ratio of male: female plants in all species examined varied with environmental conditions, mainly water availability. For example the meadow rue (Thalictrum fendleri) had a male: female ratio of almost $7: 1$ in dry sunny positions, whereas in moist shady conditions it was nearer 1:4. Mormon tea (Ephedra viridis) had a male : female ratio of $1.6: 1$ on steep, arid slopes and about $1: 2$ on alluvial bottomlands. The salt grass (Distichlis spicata) gave a ratio of about $3: 1$ in very saline conditions and about $1: 1.5$ in moderately saline areas.

These data suggest that males of all these species survive better than females in conditions of water stress, whereas the reverse is true where water is more available. Alternatively, sex determination may be environmentally controlled: Whatever the cause of this state of affairs, Freeman et al. suggest that the differentiation of niches between the sexes has adaptive significance. Reproductive success in males in these wind-pollinated species may be enhanced by their being located on exposed, dry ridges. Seed output from females, on the other hand, would be greater in conditions of improved water supply, especially later in the season.

They have not examined the role of vegetative reproduction in determining sex ratios. Putwain and Harper showed the importance of this influence in their Rumex studies and it is possible that resource allocation to vegetative reproduction in these species varies between the sexes and is differentially affected by wator availability. Ephedra, for example, spreads extensively by vegetative reproduction. Niche differentiation between the sexes of these plants has evidently occurred in response to a selective pressure, but the precise physiological or morphological cause of the variations in sex ratio remain unclear.

Dioecious plant species are not uncommon and it will be interesting to see whether more of them exhibit sexual dimorphism. Sex ratios in populations, however, may not always be the best guide to dimorphism in plants because of the influence that vegetative reproduction can have by redressing the effects of differential germination and survival. 